\title{
Attitudes toward organ donation in Arab-based population: lack of will or knowledge?
}

\author{
Rasha Almubark ${ }^{1}$, Mohammed Alghonaim², Nasser BinDhim ${ }^{3}$, Besher Attar ${ }^{4}$, Faisal Abaalkhail ${ }^{5}$, Fawaz AlAmmary ${ }^{6}$, \\ Saleh Alqahtani ${ }^{7}$

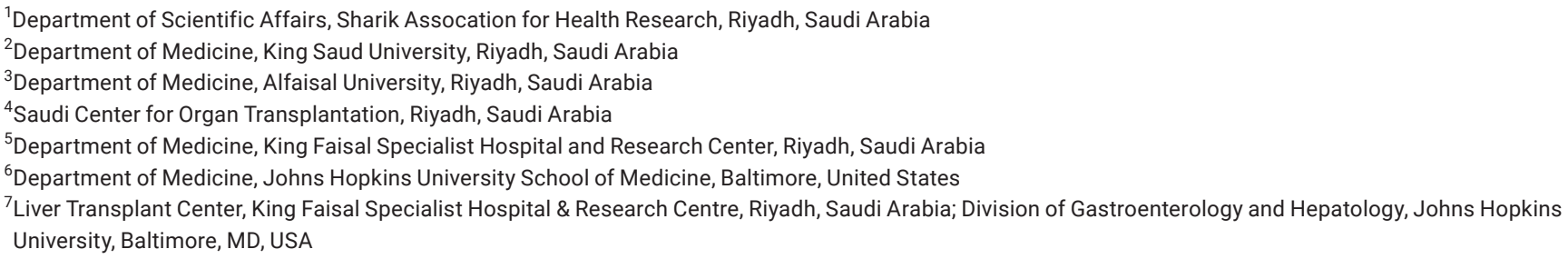

Background: Willingness toward organ donation may vary among younger and older adults. We aimed to assess and characterize awareness and attitudes about organ donation stratified by individuals age.

Methods: We conducted a cross-sectional random telephone survey with a representative sample of adults from all 13 regions in Saudi Arabia from February 12, 2021 and to March 14, 2021. The sample was stratified by individuals age (younger 18 to 35 years old and older $\geq 36$ years old).

Results: A total of 3,120 respondents completed the survey (response rate $74 \%$ ). We found that $57 \%$ of younger and $49 \%$ of older adults expressed support for organ transplantation, while $54 \%$ of the younger and $39 \%$ of older adults wanted to donate their organs. However, $3.6 \%$ of study participants had registered in the national donor database. Almost half ( $46 \%$ younger and $49 \%$ older) agreed with the primary view that it is very important for the donor and the family to agree on positions of organ donation. Physician or other healthcare worker was selected most frequently (59\% younger and $57 \%$ older) as the information source most likely to influence attitudes toward organ donation and $49 \%$ wanted to learn more about organ donation.

Conclusions: While many younger and older adults support organ donation, there is a lack of knowledge about the organ donation system. Efforts are needed for adaptation and implementation of interventions to increase knowledge and support organ donation among younger and older adults.

Corresponding author: Rasha Almubark

E-mail: ralmubark@hotmail.com

(C) The Korean Society for Transplantation

This is an Open Access article distributed under the terms of the Creative Commons Attribution Non-Commercial License (http://creativecommons.org/licenses/by-nc/4.0/) which permits unrestricted non-commercial use, distribution, and reproduction in any medium, provided the original work is properly cited. 